\title{
TRAUMATIC DISSECTING ANEURYSMS
}

\author{
BY \\ T. K. MARSHALL \\ From the Department of Forensic Medicine, University of Leeds
}

(RECEIVED FOR PUBLICATION APRIL 10, 1957)

Most dissecting aneurysms of the aorta are spontaneous, and have as their underlying pathology a degeneration of the media. Strain, physical and mental, has been suggested as a factor which precipitates their onset, but external trauma is usually exonerated. Shennan (1934) traced only six cases due to trauma, and he formed the opinion that there was rarely a clear relationship between these aneurysms and external trauma. When Mote and Carr (1942) reviewed 60 cases of dissecting aneurysm investigated in the San Francisco Coroner's Office, they concluded that external trauma was not a precipitating factor. Subsequent reviews, such as those of Gore (1952), Gore and Seiwert (1952), and Graham and Milne (1952), omit any mention of this factor.

This belief that dissecting aneurysms arise independently of external violence is wrong. Some dissecting aneurysms are precipitated by trauma and they have features which appear to differentiate them from the spontaneous kind. An awareness of these features will show that these aneurysms are not as rare as was previously supposed.

The following three cases occurred in Leeds during the last two and a half years.

\section{Case Reports}

Case 1.-A motor bus driver, aged 66, having reached the terminus, jumped out of his cab, a distance of $3 \mathrm{ft}$. from the ground, and landed heavily on his feet. As he did so he felt an excruciating pain in the lower part of his back, and, after staggering to the rear of the bus, he was helped to a seat inside. When an ambulance arrived he was in great pain and semiconscious. He was taken to hospital, where he died the following day.

At necropsy, by Dr. William Goldie, 3-4 litres of fluid blood and blood clot were found in the right pleural cavity and the right lung was completely collapsed. There was a transverse tear, less than $1 \mathrm{~cm}$. long, of the aortic intima, at the junction of the arch with the descending aorta, and dissection of the wall extended from this point distally for 6 in. to where the aneurysm had ruptured into the right pleural cavity. In this situation there was a second intimal? tear through which the aneurysm again communicated.with the lumen of the aorta. The artery was moder $-\overrightarrow{-}$ ately atheromatous (St. James's Hospital, Leeds, P.M. No. A 580).

Case 2.-A man, 60, was a passenger in a motor car which ran into the back of a stationary vehicle and was itself run into by a car from behind. The pas-? sengers were shaken considerably and the precise⿳亠丷厂 course of events was obscured by the confusion that followed. Within half an hour of the accident, how $-\overrightarrow{0}$ ever, the man complained of pains in his back as a result of the collision. It was over two hours before he arrived home, and he then found himself unableo to lie in bed because of the pains in his chest. As a consequence he spent the night in a chair before theo fire. He was seen by the doctor the next morningo and he stayed in the chair for a further 24 hours $\varrho$ when he was carried upstairs to bed. The following day he became very ill and he died in an ambulance을 while on his way to hospital 61 hours after the? accident.

At necropsy, 3 pints of blood were found in the left pleural cavity. There was a horizontal tear, $2 \mathrm{~cm}$ long. of the intima of the left wall of the aorta at the junction of the arch and the descending portion. Dis-3. section had extended upwards over the arch and down wards as far as the origin of the left renal arter! Death occurred when the aneurysm burst into the lef side of the chest. The aorta was moderately athero옹 matous. The heart weighed over $500 \mathrm{~g}$. due to hyper $>$ trophy of the left ventricle, the wall of which was. $20 \mathrm{~mm}$. thick. This was consistent with hypertension (Department of Forensic Medicine, University og Leeds, P.M. No. 4501).

Case 3.-A woman aged 75 years was crossing the्ట road at night when she was struck by a car travellin 85 at about 40 m.p.h. After the impact she was carrie about 12 yards by the vehicle. She was dead whero seen by a doctor shortly afterwards.

At necropsy, there was a fracture of the cervica? spine with severance of the cord at the level of the third cervical vertebra, extensive bruising of the tissue of the neck and mediastinum, bilateral haemothora 0 subarachnoid haemorrhage, and multiple fracture $\delta_{0}^{\circ}$ There was a transverse tear, $4 \mathrm{~cm}$. long, of the intime of the posterior wall of the thoracic aorta at the junction of the arch and the descending portion. 
small dissecting aneurysm which admitted the tip of a finger had formed. Its outer coat had ruptured and blood had entered the mediastinum (Department of Forensic Medicine, University of Leeds, P.M. No. 3508).

There is no doubt that these three dissecting aneurysms were precipitated by external violence. In the first two cases the relationship of the trauma to the aneurysm is confirmed by the onset of pain in the chest immediately after the injury. Pain radiating from the mid-thorax is a common clinical feature of dissecting aneurysm ; it may be severe, as in the first case, or mild, as in the second. In the third case it is impossible accurately to determine the onset of the aneurysm, but the necropsy findings, together with the evidence given in the coroner's court, leave no doubt that it was the result and not the cause of the accident.

Traumatic dissecting aneurysms follow tearing of the inner layers of the aortic wall, a change which can be regarded as an incomplete aortic rupture.

In spite of the apparently protected position of the thoracic aorta, rupture of its wall by trauma is not as rare as we are led to believe. Copeland (1914), Wilson and Roome (1933), Collins and D'Alessio (1938), Kleinsasser (1943), and McDonald and Campbell (1945) remark on the rarity of traumatic aortic rupture. In the necropsy practice of the Department of Forensic Medicine, University of Leeds, however, rupture of the aorta is often found. Of 85 persons who died by trauma during the five-year period of 1951-56, the aorta was ruptured in no less than $24(27.2 \%)$. The rupture was situated in 19 $(79 \%)$ at the junction of the arch and the descending part, which thus shows that this segment is the most vulnerable part of the artery.

Small intimal tears, $\frac{1}{4}-\frac{1}{2}$ in. in length, which could have been starting points of dissecting aneurysms, were also seen. In each of two persons, one a man of 40 years (P.M. 2634) buried by a fall of earth and the other a man of 23 years (P.M. 4521) who was a passenger in a car which struck a lamp standard, the aorta was torn across at the junction of the arch and the descending part and small circumferential tears of the intima were found in the adjacent distal segment. Another man had fallen down a lift shaft, and, although there was no rupture of the aorta, several dozen circumferential tears, up to $\frac{1}{2}$ in. in length, were found in the intima (P.M. 3445). Tears of this nature may heal; intimal scars believed to be healed tears have been described by Lundberg (1930) and by Peery (1942).
The commonest injury of the aorta, then, is a complete tear of its wall over an arc or the whole circumference, resulting in death from haemothorax. In some cases, however, the intima alone is torn ; this may heal or may become the starting point of a dissecting aneurysm. Death may occur, as in the third case, before dissection is appreciable or, as in the first two cases, the person may live long enough for dissection to be extensive. In common with spontaneous dissecting aneurysms it is presumably possible for traumatic aneurysms to heal. Samson (1931) described two cases of dissecting aneurysm which he ascribed respectively to trauma five years and 11 years previously.

The site of the intimal tear is important. The commonest site of aortic rupture is at the junction of the arch and the descending part. In each of the present dissecting aneurysms the intimal tear was also in this region. This indicated a traumatic origin of these aneurysms, for, contrary to general belief, the intimal tears associated with spontaneous dissecting aneurysms are infrequent at this junction. A survey of the departmental records covering the five-year period 1951-56 showed that there were 47 spontaneous dissecting aneurysms. Intimal tears in $29(62 \%)$ 'of these cases were in the ascending aorta and in $13(28 \%)$ they were in the arch. In only two cases was the tear at or near the junction of the arch and the descending aorta, and these cases had special features. In one (P.M. 3840) the dissection was slight and related to the immediate vicinity of an irregular tear in the wall of an atheromatous aorta which was extensively calcified and " ulcerated." The other case (P.M. 4112) was one of a "double aorta" where dissection had extended into the abdominal portion as far as its bifurcation.

The susceptibility of this part of the aorta to trauma depends on the anatomy of the region. The segment of the artery most commonly ruptured lies between the attachment of the ligamentum arteriosum and the origin of the first aortic intercostal arteries. The part of the artery below this segment is anchored to the spine by the pleura and the intercostal arteries. The part above it is firmly held between the great vessels of the neck and the structures within the arch, and moves with these structures whenever the mediastinum is displaced. In so doing a strain is imposed on the segment of the aorta which lies between the ligamentum and the first aortic intercostal arteries. Anything which causes violent displacement of the mediastinal structures, such as a sudden blow on 
the chest or rapid deceleration of the trunk, is likely to tear the aorta in this region.

It may be that a tear occurs more readily during systole when the aorta is tense. Two other factors may also predispose to tearing. Sometimes a calcified plaque up to $2 \mathrm{~cm}$. in diameter forms in the aortic wall at the point of attachment of the ligamentum arteriosum. When this is present, the strain on the aortic wall when the ligamentum is tensed is doubtless increased.

The other factor is the sudden and violent compression of the aorta against the thoracic spine by the parietal pleura which is tensed whenever the hilum of the left lung is displaced forwards. Under experimental conditions, tensing of the pleura extending from the left hilum to the ribs can be shown to kink the aorta at a point corresponding to the usual site of rupture.

Recognition that dissecting aneurysms can be either spontaneous or traumatic has medico-legal importance. Their accurate distinction enables civil liabilities to be apportioned and helps in the settlement of claims under accident policies. The interpretation that the aneurysm in Case 2 was traumatic enabled the widow to claim successfully against the insurers of the motorist.
Whenever the intimal tear of a dissecting aneurysm of the aorta is found at about the $\stackrel{5}{?}$ junction of the arch and the descending aorta, trauma is the probable cause.

\section{Summary}

Three cases of traumatic dissecting aneurysm are reported. Features are described by whichdissecting aneurysms of traumatic origin may be distinguished from those arising spontaneously.

I am indebted to Professor C. J. Polson for his help in the preparation of this paper. I wish to thank Dr. William Goldie for allowing me to make $=$ use of his post-mortem records of Case 1, and to Mr.R. E. Nutt, H.M. Coroner for the City of Leeds, for permission to publish these cases.

\section{REFERENCES}

Collins, J. O., and D'Alessio, C. M. (1938). New Engl. J. Med., 219, 229.

Copeland, G. G. (1914). J. Amer. med. Ass., 63, 1950.

Gore, I. (1952). A.M.A. Arch. Path., 53, 142.

Gore, and Seiwert, V. J. (1952). Ibid., 53, 121.

Kleinsasser, L.' J. (1943). Ann. Surg., 118, 1071.

Lundberg, A. (1930). Acta med. scand., 73, 19.

. ते 321 .

Mote, C. D., and Carr, J. L. (1942). Ibid., $24,69$.

Peery, T. M. (1942). Arch. intern. Med., 70, 689.

Pamson, P. C (1931). Ann. intern. Med., 5, 117.

Shennan, T. (1934). Spec. Rep.Ser. med. Res. Coun. (Lond.), No. $193 \$$

Wilson, H., and Roome, N. W. (1933). Amer. J. Surg., 22, 333. 